\title{
IMPLEMENTING QUALITY MATTERS IN AN ONLINE HEALTHCARE ADMINISTRATION COMMUNICATIONS COURSE
}

\author{
Joseph Compomizzi, Florida Atlantic University, jcomprmizzi@fau.edu \\ Adnan Chawdhry, California University of Pennsylvania, chawdhry_a@calu.edu \\ Karen Paullet, Robert Morris University, paullet@rmu.edu \\ Gary Janchenko, Robert Morris University, janchenko@rmu.edu
}

\begin{abstract}
This article examines the need for developing a multi-disciplinary approach uniting technical skills education and behavioral/baseline skills education through on-line course development and delivery. Specifically, this article explores how students in healthcare administration need cross-discipline academic experience to improve employability and workplace performance in which technical knowledge is able to be articulated for more meaningful expression in companies and organizations. This article identifies found in the literature review from students and employers and proposes how an on-line course in health administration can be designed to promote development of technical, analytical, decision-making, verbal, and presentation skills using Quality Matters Standards.
\end{abstract}

Keywords: healthcare informatics, critical thinking, health administration, QM, Quality Matters.

\section{INTRODUCTION}

Emerging trends in healthcare such as the rising costs of healthcare delivery and management, a more mobile world and thriving technological innovation are requiring universities and colleges to revisit and re-design programs in health administration. While stressing the importance of traditional disciplines with practitioners of healthcare leadership such as communication, product, service and policy, Tsekleves and Cooper (2017), make clear in their research titled "Emerging Trends and the Way Forward in Design in Healthcare: An Expert's Perspective" the importance of healthcare leaders to have knowledge and skill in problem-finding and problem-solving and technology that can contribute to healthier lifestyles and mechanisms that better support and connect people (Tsekleves and Cooper, 2017).

Additionally, Calhoun, Dollett, Sinioris, Wainio, Butler, Griffith, Pattullo, Warden and Gail (2008) provide a theory that is foundational in the business education of health administration professionals. Their competency model frames healthcare leadership development on the basis of two axes: behavioral and technical. As the research of Andrews and Higson (2010) points, however, a gap exists in the training students receive from their business curriculum and the ability to apply this knowledge in on-the-job practices. The findings of their research are affirmed in a study conducted by Conrad and Newberry in 2011 and in an article by Buhl (2014).

With this understanding, the aim of this research is to present a theoretical approach to on-line health administration course design that emphasizes development of communications, problem solving and technical/analysis skills as a response to the educational needs and requirements of health administration students and employers. This paper presents a review of existing literature, a review of core curriculum content and explanation of best practices and standards in on-line course development according to Quality Matters indicators, and an example of an on-line course at a Southeastern University that merges technical skills with behavioral/baseline skills attempting to close the education-professional practice gap with students.

\section{Healthcare Curriculum: Review of the Literature}

Pruitt et al. (2017) conducted research on developing healthcare systems curriculum utilizing a systems-based approach. Their initial assessment determined that no "gold-standard" for curriculum delivery, and that it was difficult to incorporate this into medical education (Pruitt et al., 2017). The study developed a health systems curriculum that leverages problem-based learning within a four-year systems-based medical education at a four-year 


\section{Issues in Information Systems}

Volume 20, Issue 4, pp. 175-180, 2019

institution. Pruitt et al. leveraged behavioral statements and student evaluations to address three descriptive frameworks including curriculum design, content delivery, and assessment approach to explain how problem-based learning can be used with systems-based learning.

First, effectively designing the curriculum required identifying a "professionally relevant problem that embraced complexity, mirrored medical practice, emphasized autonomous exploration, and engaged collaborative research" (Pruitt, et al., 2019). In this study, the researchers leveraged questioning, critical thinking, and problem solving by actively engaging student teams with evaluation, analysis, and determining a resolution to a problem. Second, the researchers identified content delivery leveraging 22 sessions that lasted from three to four hours each. The first two years were delivered with a weekly cadence within five-week blocks. The third and fourth years were integrated using two years of training and supplementary materials. Last, the researchers had to assess the student learning within the health systems curriculum using Entrustable Professional Activities (EPA) which included the following:

- Demonstrate advanced knowledge of US and international health systems, policy, and finance.

- Demonstrate the ability to strategize, practice, and advocate for quality improvement in patient care and health care systems.

- Integrate knowledge of health care systems into individual patient care.

- Demonstrate ability to analyze a health care environment/system and recommend changes to improve patient outcomes (Pruitt, et al., 2017)

The results of their study found the majority of first- and second-year students felt they attained working knowledge of health systems/analytics skills. In the following year, students additionally stated that the courses were well organized and administered (89.5\%), the workload provided an adequate balance between academic and personal life (87.7\%), and the assigned readings effectively enhanced their learning (82\%) (Pruitt, et al., 2017).

Healthcare professionals have strived to improve the quality of patient care through improved collaboration among each other. The idea of Interprofessional Education (IPE) involves understanding more than one professional discipline. Trying to develop this kind of program can be quite challenging with the first and most important step being the commitment from the university administration and deans / faculty from the professional disciplines. The importance of this step is to ensure proper collaborative activities among the different disciplines, logistics for content delivery, and systems used for the delivery (Birk, 2017).

Birk (2017) stated that IPE involves different types of interactive learning including collaborative, experimental, egalitarian, and reflective activities. Additionally, successful healthcare patient-oriented practice leverages the principles of accountability, responsibility, coordination, communication, cooperation, and mutual trust / respect allowing students to experience these concepts and adopt them in professional careers. Practice learning is also an integral part of IPE but with the intent that the student would meet with a healthcare team providing patient care versus clinical or field experience. This exposure would allow the student to see how professionals would plan and act in specific case scenarios (Birk, 2017). Lastly, an important component to consider is the use of computer simulations and programmed electronic learning modules. These simulations can also utilize actual human subjects through role playing which provide actual human interactions for students, although this can be less convenient then simulation learning.

Concurrently, the importance of developed business communications skills for employability of graduates is increasing. A study completed by Andrews and Higson (2010), identifies the ability to plan and think strategically and good written and verbal communication skills are key transferable soft skills and competencies integral to graduate employability. From an employer's standpoint, the Andrews and Higson study revealed that employers prefer graduates who are able to understand and analyze complex business problems and facts by applying what they have learned in the classroom. "Business acumen is one of the key things we look for the most. Many students fall down on this," commented one employer in this study's findings while another employer identified "graduates often do not know how to combine things, they do not know how things are connected to each other" (Andrews \& Higson, 2008).

To that end, the ability to apply business and technical knowledge and writing and speaking are inseparable according to Andrews and Higson (2010). Employers "expected business graduates to possess high levels of discipline specific skills synthesized with more generic interpersonal and communication competencies. In sum, 


\section{Issues in Information Systems}

Volume 20, Issue 4, pp. 175-180, 2019

they expected that, upon commencing employment, graduates would be employment-ready; equipped with the necessary skills and competencies, and able to work with the minimum of supervision" (Andrews \& Higson, 2008).

Interestingly, in this same study, students' perceptions were reflective of those of employers. Andrews and Higson (2010) found that graduates valued the hard skills they learned in the classroom. However, students identified skill gaps in their business education presenting them with difficulty once on the job. "You don't get taught enough about how to put together the formal documentation you have in employment" stated one student while another student, regarding the academic experience, responded "you don't actually get taught how to do presentations properly which would have been very useful" (Andrews \& Higson, 2008).

Like the study of Pruitt et al., a study conducted by Conrad and Newberry (2011), affirms that problem solving and using information technology are among the top five organizational communications skills needed for management and leadership of any organization. They identify that as leaders gain experience, the importance of conveying and receiving information quickly and accurately accelerates. Conrad and Newberry write that efforts to become competent communicators increases substantially as leaders grow in their jobs: "Effective communication and managers' communication skills are an extremely important issue for effective organizational behavior, relationships, and work processes. Especially managers - must possess the ability to present ideas clearly, document accurate and explicit records and notations, and create information flow channels within and outside of the business to link all vital stakeholders." According to their research, writing skills, speaking skills, technology-mediated communication, team and group communication, and negotiation skills are of most importance for managers and leaders (Conrad \& Newberry, 2011).

Regarding leadership communication outcomes, Conrad and Newberry describe that managers in modern organizations "must be good at communicating the business story convincingly" for improved analysis and performance. They conclude that leaders and managers must be able draw conceptual pictures and strategies for future planning and keep those visions at the forefront of all interactions. As Buhl (2014) reports in his article "Six Soft Skills Everyone Needs," in a survey of more than 2,000 business, employers identified problem-solving and critical observation as areas lacking in entry level employees. The survey equates these skills with technical qualifications. Buhl emphasizes the criticality of being able to articulate in writing and speaking business problems and solutions. "Be able to explain what you did, how you approached the problem, how you involved others and what the outcome was-in real, measurable results." He defines that having the skills to gather and manipulate data is not enough for industry today. Business practitioners must also be able to analyze and interpret the data, as he states, "What story does the data tell?" (Buhl, 2014).

As a degree program in business schools and colleges, graduates in health administration are held to these same competencies. Calhoun, Dollett, Sinioris, et al. (2008), in their article, "Development of an Interprofessional Competency Model for Healthcare Leadership," explain that foundational to healthcare leadership competency are two axes, behavioral and technical competencies, which identify outstanding leadership performance and sophistication. They note, for example, Accountability as a behavioral competency. Within the Accountability competency, the level one skill exhibited for this competency is "Communicates requirements and expectations" followed by setting limits, demanding high performance, confronting performance problems, and creating a culture of responsibility. On the other hand, Financial Skills are classified as technical competency. Within this technical competency, the level one measurement is "Explains financial metrics and reports." Additionally, the Healthcare Management Degree Guide (2019) cites a study by the American College of Healthcare Executives (ACHE) regarding five characteristics healthcare management employers seek in candidates. These characteristics include proper academic training and previous work experience; excellent communications skills; flexibility, adaptability, and a good organizational fit; dependability, good professional judgment and strong character; and general management skills. While the ability to practice good decision-making and problem solving is essential, the ACHE notes that the ability to prepare and present reports and proposals is paramount. Further, Bear and Skorton (2019), deduct in their article "Very few employers indicated that acquiring the knowledge and skills needed primarily for a specific field or position is the best path to success" based on a survey conducted by Hart Research Associates. They cite that the most important skills rated by employers include the ability to communicate clearly in written and verbal forms, the ability to work in teams, ethical decision making, critical thinking and the ability to apply knowledge in complex, multidimensional, and multidisciplinary settings. 
To summarize, then, the research directs instructors of health administration to the key skills and competencies required for the successful employability of business graduates. Integral with these skills and competencies is the understanding that business knowledge specific to healthcare management, and inclusive of information technology, must be accented in the curriculum design for such a degree program. Additionally, as an information system in itself, communications studies must be an important module of a health administration degree to complete this multi-discipline requirement. Following the directives of the literature, within the study of healthcare communications, development of problem-solving and critical analysis competencies, as well as, development of writing and presentation skills is essential for articulating technical knowledge and data analysis and, ultimately, for assuring student success in job performance.

\section{Quality Matters in Online Courses}

Hand in hand with curriculum design and content, universities are being required to offer varied modalities of delivery. Consequently, universities and colleges are requiring faculty to have both online and on-ground sections of the classes being taught. Federal data from over 4,700 colleges and universities which encompass over 6.3 million students in the United States indicated that students took at least one online class in the Fall of 2016 (NCES, 2018). This number represents a 5.6\% increase from the previous year. Importantly, online education has increased for 14 consecutive years. The Sloane Consortium has tracked online learning in U.S. higher education in which 80 to 100 percent course content is delivered online (Allen \& Seaman, 2013). With the push for academics to create online courses comes the push for higher quality in the materials and methods delivered.

The Marland Online, Inc. (MOL) is a non-profit organization that received a grant from the U.S. Department of Education to develop measures to help guarantee quality in online courses. The consortium developed a set of standards known as Quality Matters (QM). The QM community is comprised of over 1000 organizations from higher education, K-12 secondary, educational publishing and continuing education and professional development arenas. In order to achieve quality in the course a QM Rubric Workbook specifically for higher education was developed where specific standards are used to help ensure quality. When developing a course for higher education following the QM standards is a necessity.

The QM Higher Education Rubric was developed to assist faculty when designing online courses. The QM Rubric has eight general areas which comprise 43 standards as follows:

1. Course Overview and Introduction

2. Learning Objectives

3. Assessment and Measurement

4. Instructional Materials

5. Course Activities and Learner Interaction

6. Course Technology

7. Learner Support

8. Accessibility and Usability

A study conducted by Crews, et al. (2017) developed an online course following QM standards to gauge student perspectives on the effectiveness content delivered in an online class. The study revealed that approximately $98 \%$ of students reported that the faculty met or exceeded expectations in regard to all eight general categories. The findings indicate that if the QM standards are implemented in online course students will have a better learning experience.

\section{Healthcare Administration and Healthcare Analytics Course Development following QM}

The standards outlined by Quality Matters and the essential skills required for job success identified by students and employers, sets the framework for an on-line course inclusive of complex, multi-dimensional, and multidisciplinary learning for health administration and analytic students.

QM Standard 1: Course Overview and Introduction. Robinson and Wizer (2019) explain regarding the QM standard of course overview, "By providing background information and a helpful starting point, faculty ensure that students know early expectations, background knowledge, purpose and how they will start to learn in this course" (p. 20). To this point, a Welcome Page is provided which features a personalized message from the professor, description of the course and course objectives, required texts, and links for student support and success. 
QM Standard 2: Learning Objectives. As Robinson and Wizer (2019) explain from the QM standards: "Essential elements of course content include clearly stated and measurable learning objectives that are oriented to student learning at appropriate skill and experience levels. For example, objectives that are performable by students and indicate understanding of course concepts, skills, and knowledge Instructions that are presented in a wide array of formats that provide students with sample outcomes and detailed assignment expectations are important to ensure that objectives are met (p.21).

QM Standard 3: Assessment and Measurement. "Thorough descriptions of assignment expectations provide students with detailed information regarding significant course assignments such as tests, papers, presentations and all aspects of graded student performance requirements state Robinson and Wizer (2019, p. 21). Assignment instructions and performance requirements, then, go hand-in-hand.

QM Standard 4: Instructional Materials. "The purposeful use of instructional materials that are fully integrated to student learning events and requirements is necessary to ensure that students are able to learn course content write Robinson and Wizer $(2019$, p. 21). In the communications for health administration professionals course, each learning module features printed materials including access to e-texts; audio and visual lectures and tutorials; interactive technological exercises utilizing software such as Skype-for-Business, Knovio, Turn-it-in Peer Evaluation software, Microsoft Office and project planning software, and data analysis software such as SAS and SPSS, healthcare informatics technology; audio, visual, and technology system/software directions; and navigation tutorials.

QM Standard 5: Course Activities and Learner Interaction. To define this standard, Robinson and Wizer (2019) explain "The course design and instructional components should incorporate learner interaction that is motivational and promotes learning. We encourage faculty to find ways to provide feedback, and regular checkpoints, so that students are supported in their online work. Learning activities should advance the achievement and heighten the salience of the course learning objectives Active learning can occur with the course by optimizing relevance, value and authenticity of the learning activities, fostering collaboration and communication, and increasing mastery-oriented feedback (p.22). Weekly checkpoints are provided so that students can track their progress.

QM Standard 6: Course Technology. Course technology is utilized through the LMS. Following QM gives faculty the freedom to implement the required technology to complete the course whether it is using Skype for business of software used in the course.

QM Standard 7: Learner Support. Links to access technical support, the IT help desk, resource manuals for Turn-it-in, Skype for Business, the LMS, and other software used in the course is also available through the on-line communications for health administration professionals' course. This information is attained through an easily accessible technical support tab. A writing support tab provides links to tutors and to the university writing center through which appointments may be scheduled. One last tab providing learner support accesses the texts used in the course. To provide further support, course documentation includes a detailed syllabus explaining university, department and course policies, synopsis of major projects, grading schematics, contact information, support services, and schedule of activities with due dates and has its own module for ease of access for students.

QM Standard: Accessibility and Usability 8. Robinson and Wizer (2014) define accessibility and usability in terms of providing varied learning modalities through employment of multiple media. The on-line course provides audio and visual lectures, print material that may be downloaded for conversion, and methods of response that facilitate physical participation in the course.

\section{SUMMARY}

A review of the on-line course in communications for health administration professionals through the lens of the QM standards unveils a framework for how the gap may be closed between the theories taught in the classroom and the needs of the industry. Through the practical application of skills practiced in the classroom and assignments that 


\section{Issues in Information Systems}

Volume 20, Issue 4, pp. 175-180, 2019

require the development and practice of baseline skills focused in writing, presenting, decision-making, data analysis, research, teamwork, feedback, and project management students can be better prepared with the much sought-after soft skills that industry asks for time and time again. While this framework does not focus specifically on technical skills, it can be applied to technologies and software common to business and healthcare in order to accomplish assignment and project tasks required by any course. The result is a complex, multi-dimensional, and multidisciplinary learning experience for health administration students.

\section{REFERENCES}

Andrews, J., \& Higson, H. (2008). Graduate employability, 'soft skills' versus 'hard' business knowledge: A European study. Higher education in Europe, 33(4), 411-422.

Bear, A., \& Skorton, D. (2019). The World Needs Students with Interdisciplinary Education. Issues in Science and Technology, 35(2), 60-62.

Birk TJ. Principles for Developing an Interprofessional Education Curriculum in a Healthcare Program. Journal of Healthcare Communication. 2017, 2(1). doi: 10.4172/2472-1654.100049

Buhl, L. (June 21, 2014). Six soft skills everyone needs. Retrieved 4/24/2019 from https://www.palmbeachpost.com/article/20140621/SPECIAL/812033129.

Calhoun, J. G., Dollett, L., Sinioris, M. E., Wainio, J. A., Butler, P. W., Griffith, J. R., \& Warden, G. L. (2008). Development of an interprofessional competency model for healthcare leadership. Journal of Healthcare Management, 53(6).

Conrad, D and Newberry, R. (2012). Identification and instruction of important business communication skills for graduate education. Journal of Education for Business, v87 n2 p112-120.

Crews, T. B., Bordonada, T. M., \& Wilkinson, K. (2017). Student feedback on quality matters standards for online course design. Educause Review, 5.

Diehl, W. (2016). Online instructor and teaching competencies: Literature review for quality matters. MarylandOnline

Healthcare Management Degree Guide (2019). What qualities would make me a good healthcare manager? Retrieved 4/26/2019 from https://www.healthcare-management-degree.net/faq/what-qualities-would-makeme-a-good-healthcare-manager/.

National Center for Education Statistics. Annual report. Retrieved from https://nces.ed.gov/surveys/SurveyGroups.asp?Group=7

Pruitt, Z., Mhaskar, R., Kane, B. G., Barraco, R. D., DeWaay, D. J., Rosenau, A. M., ... \& Greenberg, M. R. (2017). Development of a health care systems curriculum. Advances in medical education and practice, 8, 745.

Robinson, D. E., \& Wizer, D. R. (2016). Universal Design for Learning and the Quality Matters Guidelines for the Design and Implementation of Online Learning Events. International Journal of Technology in Teaching \& Learning, 12(1).

Tsekleves, E., \& Cooper, R. (2017). Emerging trends and the way forward in design in healthcare: An expert's perspective. The Design Journal, 20(sup1), S2258-S2272. 